\title{
An Antarctic field study of the rheology and movement of a sea-ice floe aggregate
}

\author{
T. H. JACKA, R. ThWAITES \\ Australian Antarctic Division, Kingston, 7050, Australia \\ J. C. WILSON \\ Bureau of Meteorology, Melbourne, 3000, Australia
}

\begin{abstract}
M.V. Nella Dan was beset in ice near $66^{\circ} \mathrm{S}, 51^{\circ} \mathrm{E}$ from 27 October to 15 December 1985. The scientific investigations planned for the voyage into the seaice zone included ice thickness, concentration and extent measurements, aerial photography of the ice, a core drilling project and meteorological observations. Once beset, the programme was expanded to include repeat measurements of a small strain grid and measurements of the sea-ice drift rate. Strongly convergent local conditions had led to the initial besetment of the ship. Analysis of measurements of the strain grid area over an $11 \mathrm{~d}$ period shows that, although there is some indication that the ice field may have been divergent, opening by approximately $3.4 \%$ over this period, there are large errors in the measurements and some doubt must be placed on the reliability of this estimate. The drift speed and direction were found to be highly dependent on wind speed and direction, the drift rate being approximately $2.7 \%$ of the wind speed at an angle of about $29^{\circ}$ to the left of the wind direction.
\end{abstract}

\section{INTRODUGTION}

Within the Antarctic sea-ice zone, there are large areas of open water and of particularly thin ice even in winterspring when the ice is at maximum extent (Gow and others, 1986; Jacka and others, 1987; Allison, 1989). The movement of the sea ice on short time scales is due primarily to wind and over longer time scales, to surface ocean currents (Allison, 1989). Because of the open nature of much of the East Antarctic sea ice, it is expected that there is little stress between floes and that they move primarily in free drift.

It is important to understand the role played by the motion of Antarctic sea ice in determining the ice edge, thickness, distribution, type and concentration. Measurements of these parameters were carried out on a voyage of M.V. Nella Dan from 16 September to 31 December 1985; preliminary results have been published by Jacka and others (1987).

On 27 October, Nella Dan was progressing through an area consisting of small floes and brash ice near $66^{\circ} \mathrm{S}$, $51^{\circ} \mathrm{E}$. Under the influence of gale-force winds (Wilson, 1986), rafting and ridging of the floes occurred with the brash ice congealing the floes together in a locally convergent stress condition. Over the following $2 \mathrm{~d}$, air temperatures dropped to approximately $-17^{\circ} \mathrm{C}$ (from about $-8^{\circ} \mathrm{C}$ ) in clear, settled weather and the ice consolidated into one large aggregate approximately $20 \mathrm{~km}$ in diameter. By 29 October, the ship had become securely locked in the sea-ice field and the ice had stabilised to the point where it was considered safe enough to support humans. An "experimental" strain grid was then established. In addition, the routine glaciological and meteorological measurements, and ship position recordings continued. Nella Dan was finally freed from its trapped position with the aid of the Japanese icebreaker Shirase on 15 December.

\section{PHYSICAL GHARACTERISTICS OF THE ICE FLOE AGGREGATE}

The ice in which the ship was beset consisted of rafted floes frozen together to form one aggregate. Although the ice field was in contact with other floes to the north, there was an open-water lead between the aggregate and the fast ice abutting the Antarctic coast to the southeast. The distance from the ship to the nearest open water was about $1 \mathrm{~km}$. Figure 1 shows sea-ice concentrations in the Enderby Land region on 10 October, along with the beset position of the ship.

As a routine part of the scientific programme, ten cores were drilled through the ice field and in the surrounding area. A brief description of the salinity profiles and crystal structure has been given by Jacka and others (1987). Although the C-shaped salinity profile typical of first-year ice was not always clear, several of the profiles exhibited "stacked C" shapes indicative of multiple rafting. 


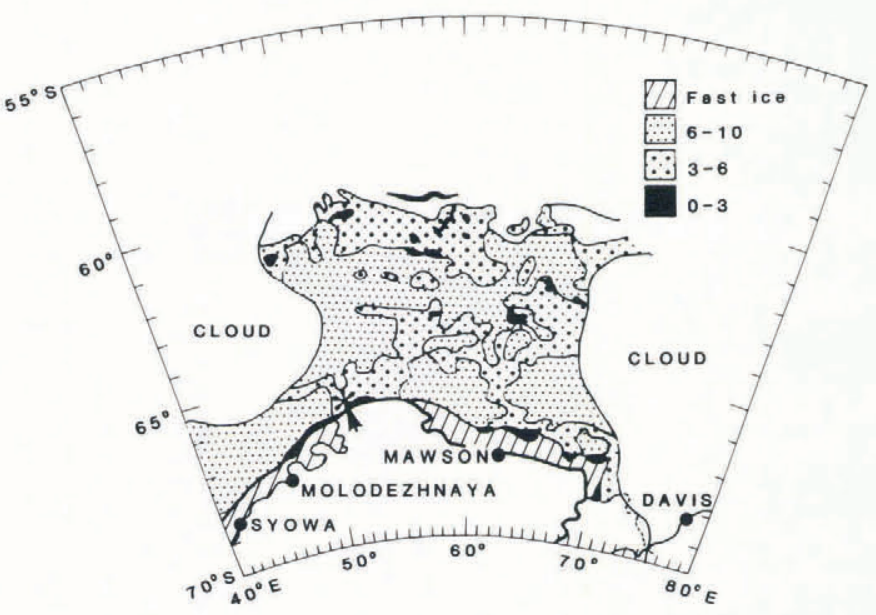

Fig. 1. Map of Enderby Land coastal region of Antarctica, showing sea-ice concentrations compiled from a Meteor 11 satellite image for 10 October 1985 (after Facka and others, 1987) and the approximate position (*) of M.V. Nella Dan while beset.

Examination of longitudinal thick sections of the cores through crossed-polarizing filters revealed that about $58 \%$ of the core ice consisted of fine-grained frazil crystals. The existence of a significant percentage of frazil ice suggests that it originated in areas of open water (Gow and others, 1982; Allison and Qian, 1985).

Ice thickness measurements (made by dropping a measuring tape with a cross-bar down boreholes) indicated values ranging from 1.10 to $2.75 \mathrm{~m}$. However, this ice thickness was invariably made up of more than one rafted floe, i.e. typical floe thicknesses were 0.5 to $0.75 \mathrm{~m}$, but, due to rafting of two, three or four floes, total thicknesses of $>2 \mathrm{~m}$ were measured. In some areas of the ice field, severe ridging had occurred. Ice ridges were up to $3 \mathrm{~m}$ high and associated keels were up to $15 \mathrm{~m}$ deep.

Temperatures were measured in five borehole. Temperatures at the snow/ice interface were between 5.7 and $-6.2^{\circ} \mathrm{C}$. The mean air temperature, measured on the ship over the time when the ice cores were drilled, was $-8.2^{\circ} \mathrm{C}$. Each of the temperature/ice-depth profiles was similar in shape, exhibiting a decrease of approximately $1^{\circ} \mathrm{C}$ from the snow/ice interface down to about $10 \%$ of the thickness, and a near linear increase from there to the ice/ water interface temperature of $-1.8^{\circ} \mathrm{C}$. It is thought that the temperature decrease exhibited in the upper $10 \%$ of the cores was due to colder temperatures some days prior to the borehole measurements.

\section{STRAIN GRID, MOVEMENT AND METEOROLO- GICAL MEASUREMENTS}

A strain grid consisting of six marker canes was placed around the beset ship, such that each marker was visible from a spot on an observation deck above the ship's bridge. Two flags were attached to each marker cane with a vertical separation of $2 \mathrm{~m}$, so that by measuring the angle subtended by the flags, the distance from the ship to the marker canes could be estimated. These measurements

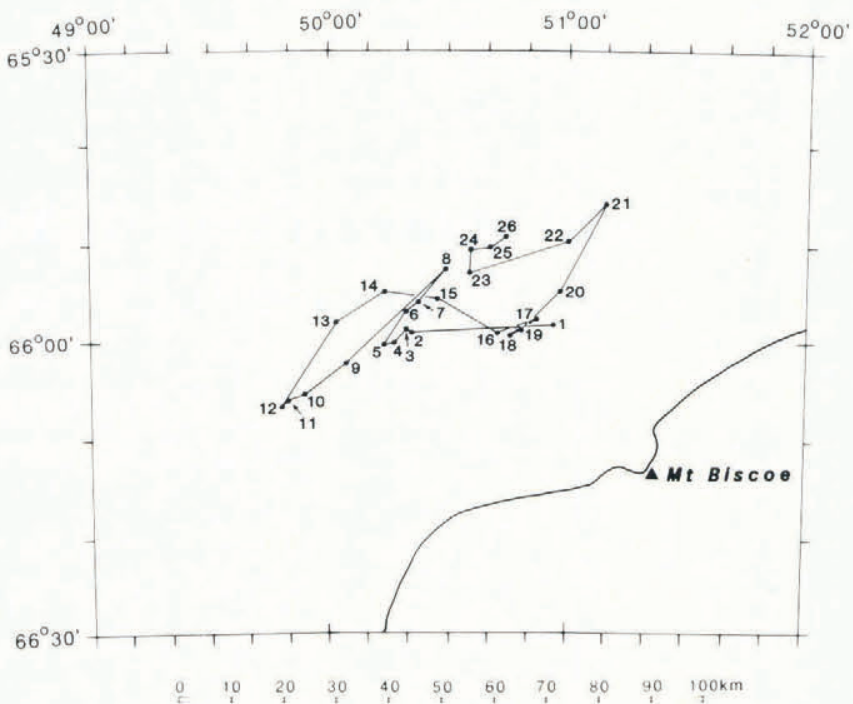

Fig. 2. Map showing drift track of M.V. Nella Dan whilst beset, along with the position of Mt. Biscoe. Day number, beginning 27 October 1985 (day number 1), is indicated beside each point.

were carried out by making multiple sextant observations over an $11 \mathrm{~d}$ period, terminating on 9 November when the ship moved a few metres in a small channel which had been cut in the ice by the ship's crew. The sextant was also used to measure the internal horizontal angles between the canes and the angles to $\mathrm{Mt}$. Biscoe, a rock outcrop on the Enderby Land coast visible from the ship and with known latitude and longitude (Fig. 2). Accurate ship position was recorded from the on-board satellite navigation system. The above measurements allow independent estimation of (a) deformation, (b) rotation and (c) translation of the ice field.

Meteorological elements, including pressure, temperature, dew point, wind speed, wind direction, cloud type, cloud cover, precipitation and water temperature, were recorded every three hours except at $2100 \mathrm{Z}$. The $2100 \mathrm{Z}$ observations of wind speed and direction, pressure and temperature were taken from the ship's log. Observations were taken at a height of $12 \mathrm{~m}$ above the surface. Observational procedures and equipment followed the guidelines laid down by the World Meteorological Organisation for shipboard observations.

\section{ANALYSIS OF MEASUREMENTS AND ERRORS}

Measurements of distances and angles, made from a height of $12 \mathrm{~m}$ above the sea ice, were adjusted to horizontal values. Addition of the horizontal angles between each strain-grid marker cane invariably produced a result of $>360^{\circ}$. The mean and standard deviation of the total angle for all measurements of the strain grid were $365.8^{\circ}$ and $1.2^{\circ}$, respectively. Measurements were taken by three different observers and there was no observer bias. The discrepancy of $5.8^{\circ}$ (over six measurements) was therefore assumed to be a constant instrument bias, and horizontal strain grid angle measurements were adjusted linearly. An error of $\pm 1.2^{\circ}$ was assigned to each internal strain grid horizontal measurement. 
Strain grid distance estimates were made by measuring the vertical angle subtended by the two flags $2 \mathrm{~m}$ apart on the marker canes. At least three measurements were made of the subtended angle in all cases. The greatest spread of observations attained within a set of verticalangle measurements was $40 \mathrm{~s}$, which over a distance of $250 \mathrm{~m}$, yields an error of $\pm 3.1 \mathrm{~m}$.

From the latitudes and longitudes of the ship's positions and of Mt. Biscoe, bearings (and distances) of the mountain from the ship were calculated. Sextant measurements of the horizontal angle between strain grid canes and Mt. Biscoe were then used to calculate the orientation of the strain grid. The accumulated sextant error of $5.8^{\circ}$ over six observations noted earlier, along with the measurement standard deviation of $1.2^{\circ}$, suggests that an error of approximately $\pm 2.2^{\circ}$ should be expected on the strain grid orientation observations.

\section{RESULTS}

In order to examine the convergence/divergence of the ice field, the area of the grid was estimated for each set of measurements. The grid area consists of six triangles. The area of each triangle, $A$, is given by

$A \pm \Delta A=(1 / 2) l_{1} l_{2} \sin \varphi$

$$
\pm(1 / 2)\left[\sin \varphi\left(l_{2} \Delta l_{1}+l_{1} \Delta l_{2}\right)+l_{1} l_{2} \cos \varphi \mathrm{D} \varphi\right],
$$
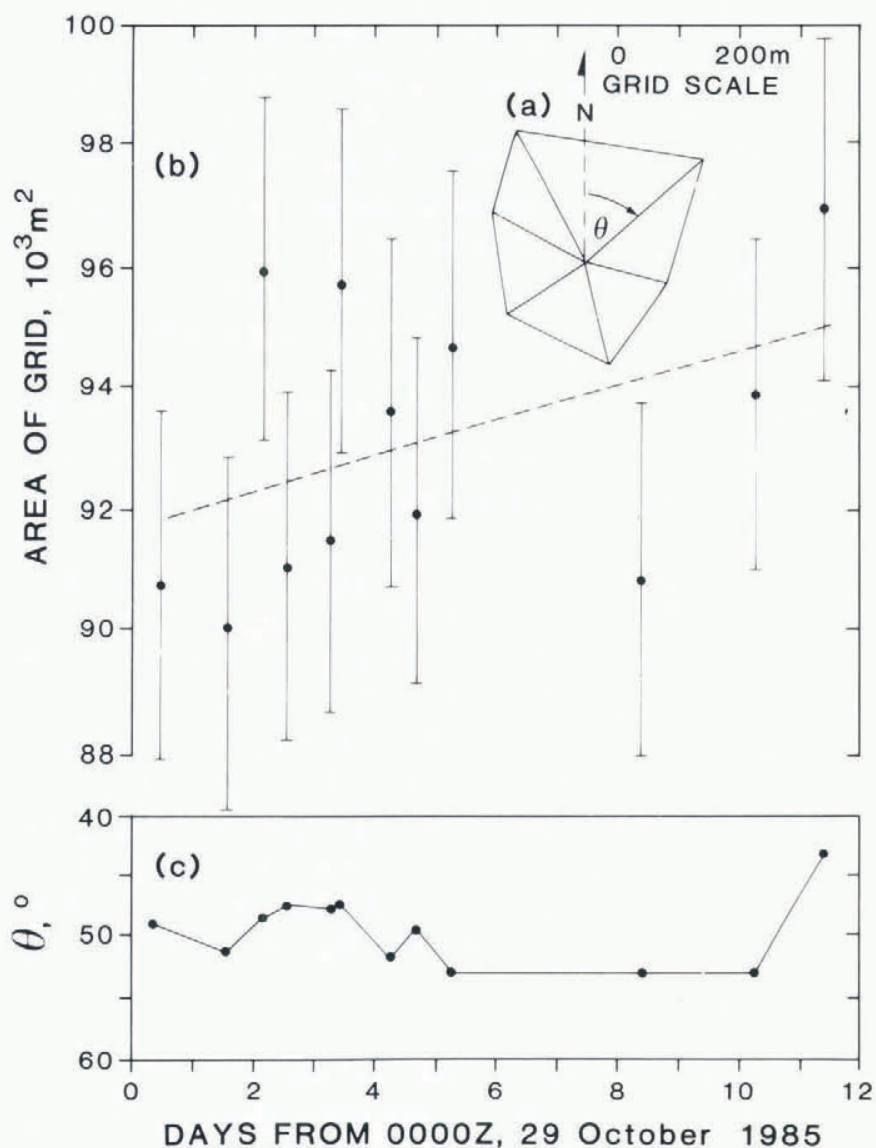

Fig. 3. (a) Schematic illustration of the strain grid established on 29 October 1985; (b) plot of area of the grid as a function of time, showing measurement error bars and regression line (dashed) with correlation coefficient, $r=0.42$; and (c) plot indicating rotation, $\theta$, of the grid with respect to true north. where $\varphi$ is the angle subtended by the two distance measurements, $l_{1}$ and $l_{2} . \Delta l_{1}, \Delta l_{2}$ and $\Delta \varphi$ are errors in the measured parameters and $\Delta A$ is the error in the area estimation. Figure 3 shows (a) the shape and orientation of the strain grid and (b) the total grid area plotted with the calculated error bars as a function of time. The regression line of Figure $3 \mathrm{~b}$ (correlation coefficient, $r=0.42)$ has a slope of $281 \mathrm{~m}^{2} \mathrm{~d}^{-1}$, indicating that the ice field is divergent, opening by approximately $3.4 \%$ over the $11 \mathrm{~d}$ measurement period. However, the errors in the area calculations are larger than the estimated divergence and, thus, this result must be treated with caution.

Measurements of the orientation of the ice field are shown in Figure 3c. For the entire measurement duration, the orientation of the grid did not change by more than $10^{\circ}$ and for most of the time, rotated by less than $5^{\circ}$.

A mean wind vector was calculated from the eight measurements of wind speed and direction collected between and including $0000 \mathrm{Z}$ and $2100 \mathrm{Z}$ each day. Figure $4 \mathrm{~b}$ shows a plot of the mean drift velocity of the floe aggregate each day (calculated from ship position at $0000 \mathrm{Z}$ ) as a function of mean wind speed measured at a height of $12 \mathrm{~m}$ above the surface. A linear relation $(r=0.80)$ between these two parameters is exhibited, indicating an ice speed of $2.7 \%$ of the wind speed; cf. early observations by Nansen (1902) who found ice drift speeds of $2 \%$ of the wind speed, and the calculated curves of Hibler (1985) showing floe drift speed as a function of geostrophic wind speed.

The turning angle (bearing of the mean wind heading minus the bearing of the ice-field heading) is also plotted as a function of wind speed in Figure 4a. At low wind speeds, the turning angle was variable, possibly because these low speeds are local effects not representative of the forces driving the pack-ice drift and also because ocean surface current effects on the ice field may dominate wind effects. The mean turning angle for the measurements at speeds greater than $2 \mathrm{~m} \mathrm{~s}^{-1}$ was $28.8^{\circ}$, i.e. the floe aggregate drift direction was $28.8^{\circ}$ to the left (southern hemisphere) of the wind direction. This angle compares with Nansen's (1902) measurement of $30^{\circ}$ (clockwise in the northern hemisphere) and with Hibler's (1985) calculations of turning angles between $60^{\circ}$ and $10^{\circ}$, depending on ice thickness and geostrophic wind speed.

Accurately tracked drifting buoys have recently added significantly to the data on sea-ice drift rates in Antarctic seas (e.g. Allison, 1989). However, direct measurements of wind direction and speed are sparse. Most studies of the effects of wind speed and direction on the sea-ice drift have used the geostrophic wind, which, because it neglects friction, may give an over-estimate (by as much as approximately $10 \%$ ) of the actual wind speed and a greater turning angle (by about $10^{\circ}$ ).

\section{CONCLUSIONS}

M.V. Nella Dan became beset on 27 October 1985 in ice which, under the influence of strong easterly winds, was locally convergent, leading to rapid closing and freezing. A small strain grid was established on the ice and repeated measurements of the grid indicated that from 29 October 

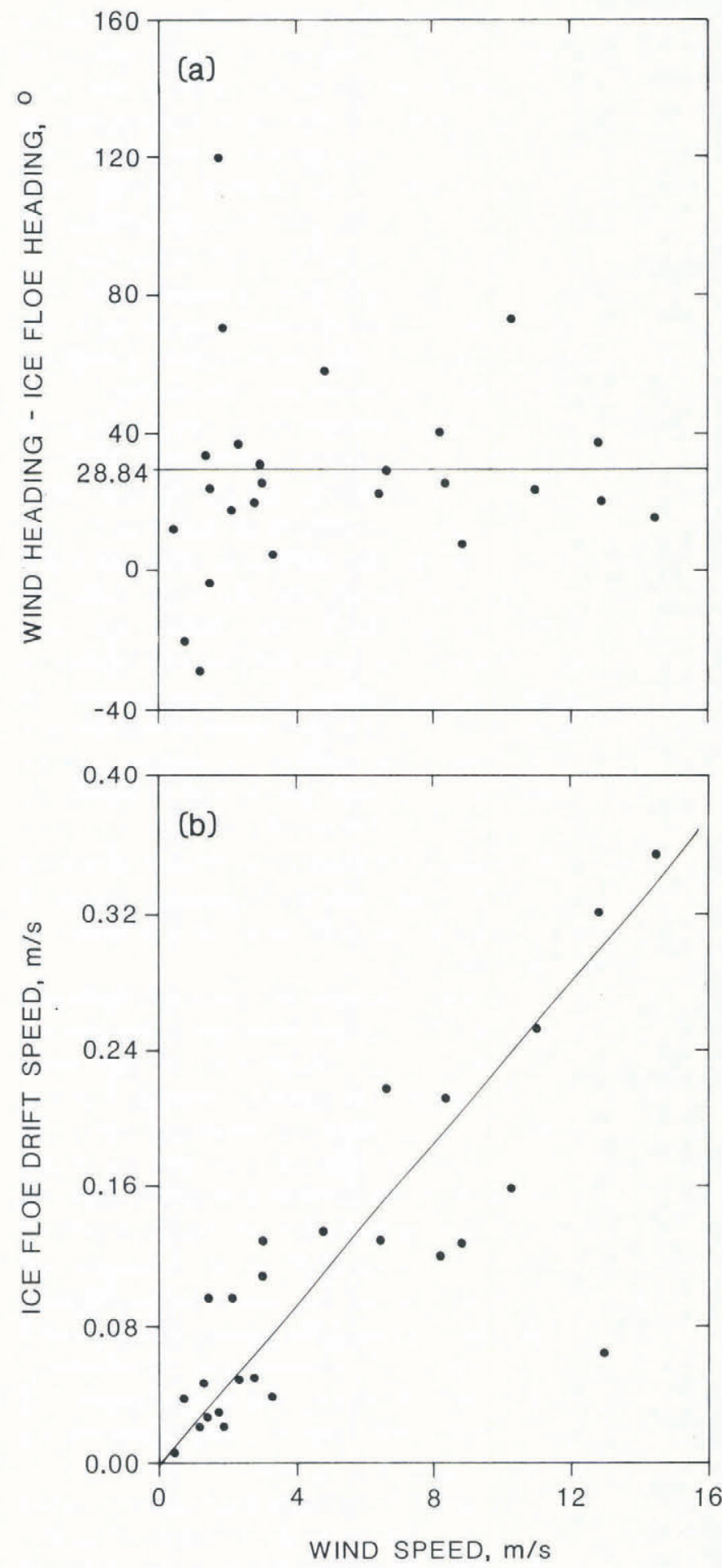

Fig. 4. Plots, as functions of mean daily wind speed measured at a height of $12 \mathrm{~m}$, of (a) the turning angle of the ice floe with respect to the wind direction and (b) the mean daily ice floe velocity.

to 9 November, the ice field was weakly divergent, opening by approximately $3.4 \%$ over the $11 \mathrm{~d}$ period.
However, because of the small size of the grid and of the measurement errors, this result should be treated with caution.

Examination of the ice-field drift speed and direction in comparison with measured wind speed and direction revealed that the drift speed was approximately $2.7 \%$ of the wind speed and at an angle of about $29^{\circ}$ to the left of the wind direction. These values would seem to indicate that in this area, about $40 \mathrm{~km}$ from the Antarctic coast, and in ice concentrations of 3 to 6 tenths (see Fig. 1), the floe aggregate was in free drift.

\section{ACKNOWLEDGEMENTS}

We thank two anonymous reviewers who suggested (1) a more thorough error analysis of the strain grid measurements and (2) calculation of the area of the grid. The subsequent calculations led to significant improvements to the paper. Some of the analysis for this paper was carried out at Thayer School of Engineering, Dartmouth College, Hanover, NH. T.H.J.'s visit to Dartmouth College was sponsored in part by the Australian-American Education Foundation under the Fulbright Award programme.

\section{REFERENCES}

Allison, I. 1989. Pack-ice drift off East Antarctica and some implications. Ann. Glaciol., 12, 1-8.

Allison, I. and Qian Songlin. 1985. Characteristics of sea ice in the Casey region. ANARE Res. Notes 28, 47-56.

Gow, A.J., S.F. Ackley, W.F. Weeks, and J.W. Govoni. 1982. Physical and structural characteristics of Antarctic sea ice. Ann. Glaciol., 3, 113-117.

Hibler, W.D., III. 1986. Ice dynamics. In Untersteiner, N., ed. The geophysics of sea ice. New York, Plenum Press, 577640.

Jacka, T.H., I. Allison, R. Thwaites, and J.C. Wilson. 1987. Characteristics of the seasonal sea ice of East Antarctica and comparisons with satellite observations. Ann. Glaciol., 9; 85-91.

Nansen, F. 1902. The oceanography of the north polar basin. In Nansen, F., ed. The Norwegian North Polar Expedition 1893-1896. Scientific Results, Vol. 3, No. 9. Christiania, Jacob Dybwad.

Wilson, J.C. 1986. Meteorological factors associated with the besetment of the M.V. Nella Dan, off the Antarctic coast, October 1985. In American Meteorological Society. Second International Conference on Southern Hemisphere Meteorology, December 1-5, 1986, Wellington, New Zealand. Boston, MA, American Meteorological Society, 127-129.

The accuracy of references in the text and in this list is the responsibility of the authors, to whom queries should be addressed. 